\title{
Ficções de análise: detalhe, intriga visual e "arqueologia hermenêutica" em Tren de sombras (1997)
}

\section{Luiz Carlos Oliveira Jr.}

\section{Resumo}

0 artigo aborda o que podemos chamar de uma "ficção de análise": uma narrativa concentrada na investigação de uma imagem ou de um conjunto de imagens, as quais são examinadas por um olhar exacerbado e curioso, faminto por intrigas ópticas e descobertas surpreendentes. Veremos como esse olhar típico da modernidade visual no Ocidente se manifesta em Tren de sombras (Jose Luis Guerin, 1997), cujos principais precursores cinematográficos são Blow up (Michelangelo Antonioni, 1966) e A hipótese do quadro roubado (Raul Ruiz, 1978). 0 objetivo é mostrar como esses filmes fornecem um modelo experimental de investigação visual e análise metafílmica.

\section{Palavras-Chave}

Suporte fílmico. Investigação óptica.

Hermenêutica estética.

\section{A expulsão do paraíso}

Em Tren de sombras: El espectro de Le Thuit, de 1997, José Luis Guerin apresenta o que podemos chamar de uma "ficção de análise": uma narrativa concentrada na investigação de uma imagem ou (como é o caso aqui) de um conjunto de imagens, as quais são examinadas por um olhar exacerbado e curioso, faminto por intrigas ópticas e descobertas surpreendentes - um olhar informado por uma das atitudes mais determinantes da experiência visual moderna, a saber, a febre detetivesca a que Victor I. Stoichita (2015) deu o nome de "efeito Sherlock Holmes".

Filmes como Blow up - Depois daquele beijo (Blowup, 1966), de Michelangelo Antonioni, e A hipótese do quadro roubado (L'Hypothèse du tableau volé, 1978), de Raúl Ruiz, que se organizam em torno da exegese obsedante de uma fotografia e de uma coleção de pinturas, respectivamente, podem ser considerados alguns dos pilares desse "gênero" de filme.

Luiz Carlos Oliveira Jr. I luizcarlosoliveira@gmail.com Doutor em Meios e Processos Audiovisuais pela Universidade de São Paulo - USP, Brasil. Pós-doutorando no Departamento de Artes Plásticas da USP.
As imagens que alimentam as ficções de análise vistas no cinema possuem antecedentes na 
história da pintura. Podemos pensar, por exemplo, nos dispositivos simbólicos do maneirismo (a grande fonte de inspiração de Ruiz em A hipótese do quadro roubado), assim como nos significados alegóricos que muitos pintores holandeses do século XVII (Gerrit Dou, Pieter de Hooch, Samuel van Hoogstraten, Nicolas Maes, Pieter Claesz) disfarçavam e diluíam na aparente banalidade naturalista de suas cenas de interior e naturezas mortas. Na segunda metade do século XIX, outro tipo de mistério pictórico se configuraria nas intrincadas tramas visuais dos quadros de Manet, que parecem sempre apontar para um "fora de quadro", para uma cena que, situandose além dos limites do espaço figurado, cria uma abertura na representação, uma ausência sobre a qual o observador se põe a especular. Essas imagens são portadoras de uma energia semântica incaracterística, que as torna, destarte, um foco privilegiado para investimentos interpretativos.

No caso de Tren de sombras, filme que transita entre a ficçãa, 0 documentário e 0 ensaio experimental, as imagens analisadas derivam de um suposto material de found footage: Guerin revisita as filmagens amadoras feitas em uma casa de campo na Normandia por um próspero advogado parisiense desaparecido em circunstâncias misteriosas em 1930, nas imediações do lago Le Thuit. Os primeiros vinte minutos de Tren de sombras consistem nas cenas familiares captadas por Gérard Fleury (assim se chamava 0 advogado) entre 1928 e 1930: passeios, banhos de lago, refeições, brincadeiras inocentes, repousos frugais, retratos de família "imagens rudimentares, porém vitais, que fazem relembrar a infância do cinema", conforme define a cartela de início acrescentada por Guerin (na qual se lê também que o material, extremamente danificado pela umidade recebida ao longo de várias décadas de má conservação, foi restaurado com parte dos recursos obtidos para a realização do filme). Vez ou outra, como nas saynètes do cinema dos primórdios, alguém encena uma pequena performance cômica para a câmera. A simplicidade e o frescor típicos dos primeiros registros amadores aparecem magnificados pelo bom domínio técnico e pela notável sensibilidade plástica de Fleury. No momento em que se comemorava o primeiro centenário do cinema e discutia-se tanto seu passado como seu (incerto) futuro, Guerin encontrou nesse singelo material familiar um verdadeiro tesouro: um reservatório de imagens em que se podem ainda apreciar, intactas, as potências originais do cinematógrafo.

Terminado o filme familiar, surgem imagens coloridas e atuais, filmadas por Guerin na mesma cidade normanda onde os registros familiares foram feitos. Quase setenta anos se passaram; o lugar é o mesmo, mas já totalmente diferente. Uma série de vistas da cidade e dos seus arredores realça a exuberante vegetação de outono, com suas folhas mudando de cor sob uma luz crepuscular que contrasta com a luminosidade abundante das férias de verão filmadas por Fleury no passado. Depois de diversos planos de paisagem, a câmera redescobre, enfim, a casa 
de campo da família Fleury, como que deixada no mesmo lugar onde 0 tempo a esqueceu. 0 vento balança as árvores e derruba folhas que se somam às outras tantas que já formam um tapete colorido no jardim. Ovelhas atravessam o campo. A tranquilidade reina em silêncio. A câmera de Guerin, em seguida, migra para dentro da casa, 0 interior que, nas imagens de arquivo, nunca era mostrado (lá só havia cenas ao ar livre).

Não há ninguém na casa. A presença da família se restringe às fotografias expostas em portaretratos nos móveis da sala. Enquanto explora 0 ambiente, a câmera parece atraída por alguns objetos em particular: espelhos, relógios, sombras, retratos, ou seja, superfícies reflexivas, signos de inscrição do tempo (da sua passagem), formas de duplicação da realidade visível, como se 0 objetivo fosse convidar os fantasmas do filme de família a retornarem. Resulta disso uma longuíssima sequência em que Guerin dá vazão a um ousado experimentalismo formal, buscando um ritmo de montagem calcado muito mais em uma plasticidade musical do que em critérios de significação. Ele usa as sombras projetadas na parede e movimentadas pelo vento como fonte da mais simples e cativante poesia cinematográfica.

Essa segunda parte terminará com 0 ressurgimento das imagens do filme de família. Guerin retorna aos registros do Sr. Fleury, mas agora com outro olhar, ou melhor, com outra disposição de olhar: qual um detetive de imagens, ele parece buscar alguma coisa no filme familiar, alguma cena escondida. Pela observação detalhista das trocas silenciosas, dos sorrisos cúmplices, dos gestos ambíguos, dos olhares lançados para fora de campo, Guerin descobre (inventa?) uma ligação secreta entre três personagens do filme amador: a jovem Hortense, o tio Etiénne e uma das empregadas da família, que parece ser a babá das crianças mais novas. Um misterioso triângulo se cria. 0 found footage se torna alvo de um trabalho quase maníaco de investigação visual e decomposição analítica. Nenhum comentário verbal é acrescentado (gráfica ou oralmente) às imagens; assistimos a um trabalho inteiramente cinematológico, executado diretamente nas imagens (na sua matéria, nas suas durações e velocidades). Efeitos estéticos que remetem aos filmes de vanguarda do cinema silencioso se associam à atitude investigativa, de modo que pesquisa plásticoformal e enquete "policial" passam a coincidir. Nas manipulações de imagem operadas por Guerin, sentem-se ecos de Jean Epstein, Dziga Vertov e Hans Richter: sobreimpressões, colagens, planos abstratos, split screen, congelamentos de fotograma, câmera lenta, imagem acelerada, ampliação óptica de detalhes, repetições, retornos insistentes sobre um mesmo movimento ou sobre um mesmo fragmento de plano. 0 material de arquivo é submetido a um princípio de desgaste mecânico: ele é exaurido, exigido em todas as suas potências de figuração, como se as incessantes idas e vindas, pausas, acelerações, ampliações, etc., pudessem desbloquear as resistências da imagem para fazê-la manifestar sintomas latentes, 
informações ocultadas nos interstícios. É como se o material de base de um filme de Péter Forgács fosse retrabalhado por Ken Jacobs de Tom, Tom, the Piper's Son (1969), tendo por objetivo a revelação de um mistério comparável àquele que o protagonista de Blow up descobre em uma série de fotografias feitas em um parque.

Mas qual será 0 segredo que 0 jardim dos Fleury esconde? E que relação isso pode ter com a morte do advogado? Mesmo que a trama seja pura invenção de Guerin, a interrogação do olhar é suficiente para que a inocência do filme de família seja perturbada e sua aparente harmonia, irreversivelmente desviada. 0 filme sofre a ação de um olhar. A partir de então, já não pode ser a celebração inocente da vida que passa; precisa conotar alguma coisa, lidar com um "bônus" de sentido. As imagens não mudam: as crianças continuam alegres, as paisagens continuam belas, o sol continua a brilhar no rosto fotogênico da jovem Hortense. Mas sabemos agora - ou fomos levados a pensar assim - que alguma coisa ameaça esse mundo idílico. A insignificância original do filme foi perturbada, pervertida por uma elaboração secundária. Guerin expulsa o registro familiar daquele "Éden cinematográfico onde a angústia com a montagem do olhar ainda era desconhecida" (BONITZER, 1982, p. 47). Seu filme pode ser visto como um manual de como "hitchcockizar" um mero registro amador despretensioso: não é preciso acrescentar novas imagens às já existentes, basta investigar estas últimas, explorá-las pelo prisma de um olhar intencionado.

\section{0 demônio do filme}

A démarche de Guerin em Tren de sombras está diretamente relacionada à promessa de indicialidade que acompanha o paradigma da imagem fílmica (e que não tem o mesmo peso na era digital). Nos tempos da invenção da fotografia e, mais tarde, do cinema, a versão da mimese oferecida pelo registro fílmico implicava a "certeza" de que algo ficara gravado nele por um processo indiciário que garantia que uma parte da realidade visível se transferisse para a superfície fotográfica mediante as reações fotossensíveis do material às impressões luminosas recebidas. Por conta dessa dimensão ontológico-fenomenológica a ele identificada, 0 filme, enquanto meio e suporte, rapidamente se tornou o lugar de manifestação da evidência de um real que passou e, enquanto passava, deixou sua marca na película. É essa "emanação do real passado" (BARTHES, 1984, p. 132) que, trazendo uma espécie de "certificado de presença", incita 0 olhar a querer descobrir a "verdade" na imagem, a varrer sua superfície à procura do que há por trás, do que lá ficou registrado em estado latente, à espera de ser revelado. Afinal, na fotografia e no cinema, em virtude da natureza mecânica/ inconsciente do registro, a informação guardada é "impura", pois vem contaminada pelas "centelhas de acaso" que a câmera não consegue evitar (RUIZ, 2005, p. 33). Uma nuvem de poeira, de 
elementos insignificantes, se infiltra na imagem e ultrapassa a forma desejada. Por não obedecer estritamente às intenções do operador, a imagem fílmica retém aspectos do mundo que o olhar já havia descartado, ou sequer havia notado, mas que ressurgem no momento da revelação-ampliação. É precisamente essa característica a responsável pela vertigem hermenêutica que costuma se vincular ao registro fílmico. Em todo filme, mora um demônio da interpretação disposto a atiçar 0 olhar e fazê-lo sair à procura do segredo que deve estar lá, encoberto no "inconsciente" da imagem, aguardando para ser desrecalcado.

Tren de sombras, típico representante da vertigem de interpretação engendrada pelo suporte fílmico, apresenta-se como uma análise intensiva do inconsciente óptico do filme de férias da família Fleury. Guerin perscruta as ligações perigosas que a não montagem do registro de família sugeria sem ousar articular. As bobinas de Fleury são deslocadas de sua função original para assimilar um desejo de ficção, de trama, de peripécias narrativas. 0corre um processo de narrativização de um filme que, a priori, é a-narrativo, misto de cinematografia de atrações com algo ainda menos estruturado um conjunto desordenado de planos, junção aleatória de registros soltos que, não raro, obedecem a uma concepção fotográfica e "primitiva": em diversos momentos, as pessoas posam estaticamente para a câmera de Gérard Fleury como posariam para um fotógrafo.
0 desafio aceito por Guerin, então, é 0 de tentar gerar narratividade nessas imagens, tirando-as do magma primordial em que todo 0 interesse que podiam despertar dizia respeito à beleza espontânea de sua luz, de suas paisagens, de seu impressionismo nä̈f. Nesse sentido, as opções de Guerin são o contrário do que se vê na maioria dos filmes experimentais de found footage que recuperam imagens do cinema narrativo/representativo, os quais dissolvem a estrutura ordenadora dos filmes para reempregar suas imagens como puro dispêndio de energia e modulação de intensidades, frequentemente submetendo-as a deformações plásticas (BLÜMLINGER, 2013). Guerin, diferentemente, faz o filme de arquivo passar da mostração à narração (JOURNOT, 2007, p. 271).

A insistência no vento e na névoa noturna como motivos visuais predominantes na segunda parte do filme (a que se passa na casa vazia) evidencia 0 aspecto fantasmático e onírico dos momentos de espera e dúvida compreendidos entre a primeira visão do arquivo de família e a sua posterior revisão. Inicialmente pensada em termos de fenomenalidade empírica e documento bruto da realidade objetiva, a imagem do filme familiar ainda ressoando na memória do espectador, mas já sendo suplantada pelas outras imagens que o presente da experiência da projeção oferece começa a se deixar invadir por fantasmas. Essa sequência, temporalmente dilatada, dá forma poética ao suspense inerente ao paradigma fílmico e correspondente ao "processo técnico 
da revelação, que é necessariamente inscrito na duração, com suas fases sucessivas obrigatórias, indo da imagem latente à imagem revelada $\mathrm{e}$ depois à imagem fixada" (DUBOIS, 2012, p. 89). Antes de reaparecer e ser analisado pela lupa de Guerin, 0 antigo filme de família fica flutuando entre 0 real e 0 imaginário. E, quando finalmente ressurge, as virtualidades que suscitou naquele período de latência servem de combustível para as especulações de Guerin. 0 filme de Fleury não pode doravante ser apreciado apenas como o documento objetivo de um evento passado; ele inclui também as incertezas acumuladas no intervalo entre a visão e a revisão. É a própria noção de objetividade e indexalidade da imagem fotoquímica que aí se vê estremecida.

\section{Detalhe, punctum, mancha}

Em seu estudo sobre os diferentes aspectos do detalhe na arte pictórica, Daniel Arasse fala das surpresas e estranhezas que a observação minuciosa dos pormenores de um quadro pode revelar. Aproximar o olho da pintura pode fazer sobressair o detalhe que ressignifica 0 discurso do quadro tal como ele era percebido enquanto se respeitava à "boa distância". 0 detalhe pode tanto trabalhar em harmonia com o conjunto, contribuindo humildemente para a mensagem global da obra, quanto desafiar essa mensagem, perturbá-la, oferecer-lhe resistência e deslocar seu sentido: neste caso, o detalhe intervém na percepção do quadro "como um momento fulgurante que provoca um suspense do olhar e de sua errância, uma estase e um êxtase" (ARASSE, 1996, p. 244), momento de parada do olhar e arrebatamento.

É exatamente o que acontece em Tren de sombras, com as devidas transposições para o registro fílmico: a "aproximação do olho" e a percepção arrebatadora de um detalhe obrigam a uma parada do olhar, o que aqui ganha um sentido literal, já que Guerin, em diversos momentos, efetivamente interrompe 0 desfilamento do filme no projetor, suspende a passagem rápida dos fotogramas, a sucessão que cria a ilusão de movimento no cinema, instituindo, em vez disso, uma imagem congelada, fixa, a qual se disponibiliza ao olho para um exame dos detalhes que, no fluxo ininterrupto da situação de exibição do filme, tornam-se inapreensíveis. Guerin não apenas congela a imagem, como ainda isola um pormenor e 0 amplia opticamente, retirando-o da área indistinta em que se perdia na vegetação de fundo e fazendo-o ocupar toda a tela, praticamente desnudado por uma lente de aumento. É assim que ele nos convence da presença da babá na profundidade de campo de um plano que havíamos visto anteriormente, porém sem que nos ocorresse depositar atenção em tal detalhe. Nosso olhar estava concentrado na cena que acontece em primeiro plano: Hortense passa de bicicleta e acena para 0 tio Etiénne, que tira 0 chapéu em sinal de cumprimento (Figura 1). Agora, isolada e fermentada pelas intervenções ópticas de Guerin, a figura da babá, outrora uma 
pequenina mancha sem definição, aparece com mais nitidez em fotogramas que vibram na tela por alguns segundos (figuras 2 e 3), antes de serem como que devorados pelos defeitos da película (Figura 4). A figura, portanto, é salva da invisibilidade em um primeiro momento, mas logo retorna, como a confirmar sua vocação para a desaparição.

Figuras 1-4: 0 detalhe fermentado e depois carcomido pelo fungo.
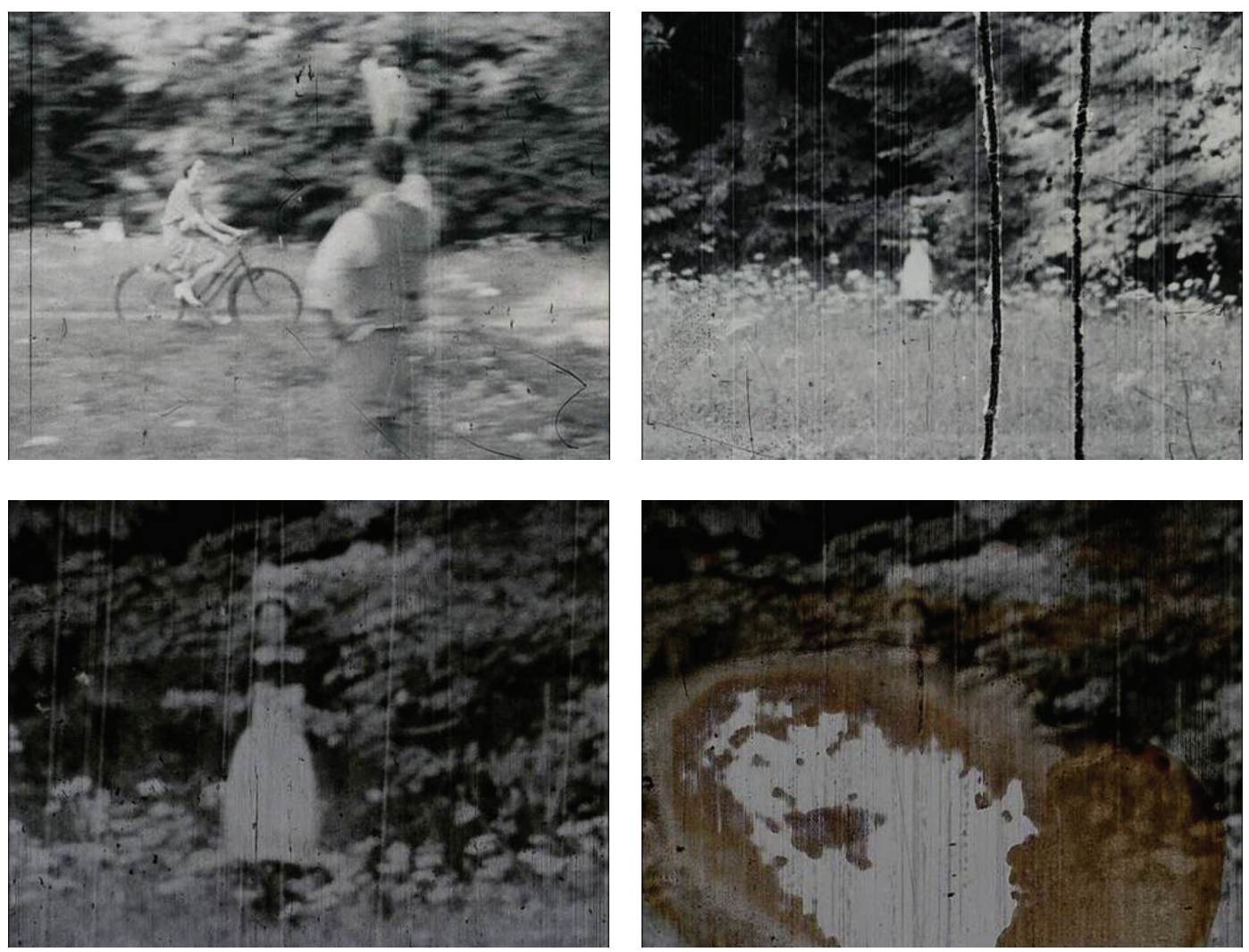

Fonte: Tren de sombras, José Luis Guerin, 1997.

Em outro momento do filme, Guerin interpreta os olhares de soslaio que duas crianças dirigem para o fora de campo (figuras 5 e 6 ). Ele conclui que elas observam alguma coisa que acontece no jardim dos fundos e, para sua sorte, descobre que tal acontecimento está a se refletir no vidro atrás das crianças. Ampliando o reflexo no vidro, Guerin flagra uma cena suspeita: o tio Etiénne caminha ao lado da babá e parece galanteá-la (figuras 7 e 8). Mais uma vez, Guerin operou uma decupagem interna na imagem de arquivo, gerando um plano-detalhe pela ampliação de um pormenor dela recortado. 


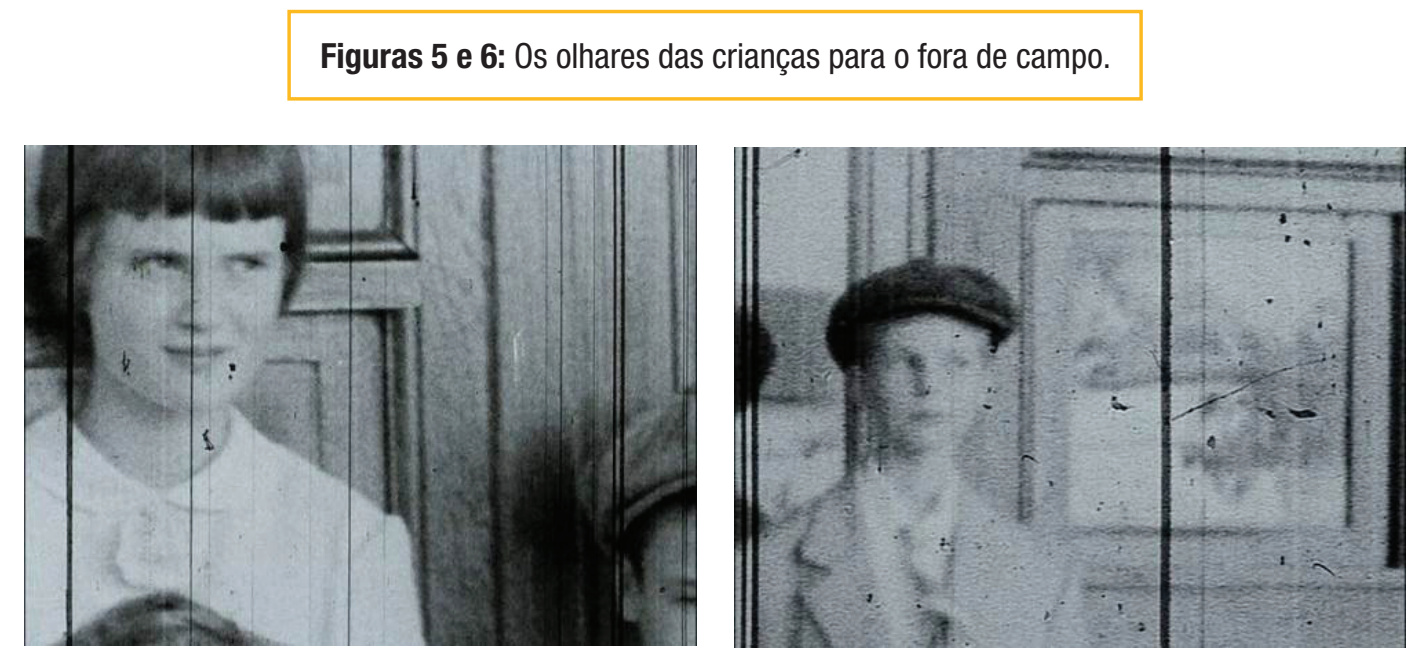

Fonte: Tren de sombras, José Luis Guerin, 1997.

Figuras 7 e 8: 0 reflexo no vidro: a cena "suspeita" envolvendo Etienne e a babá.
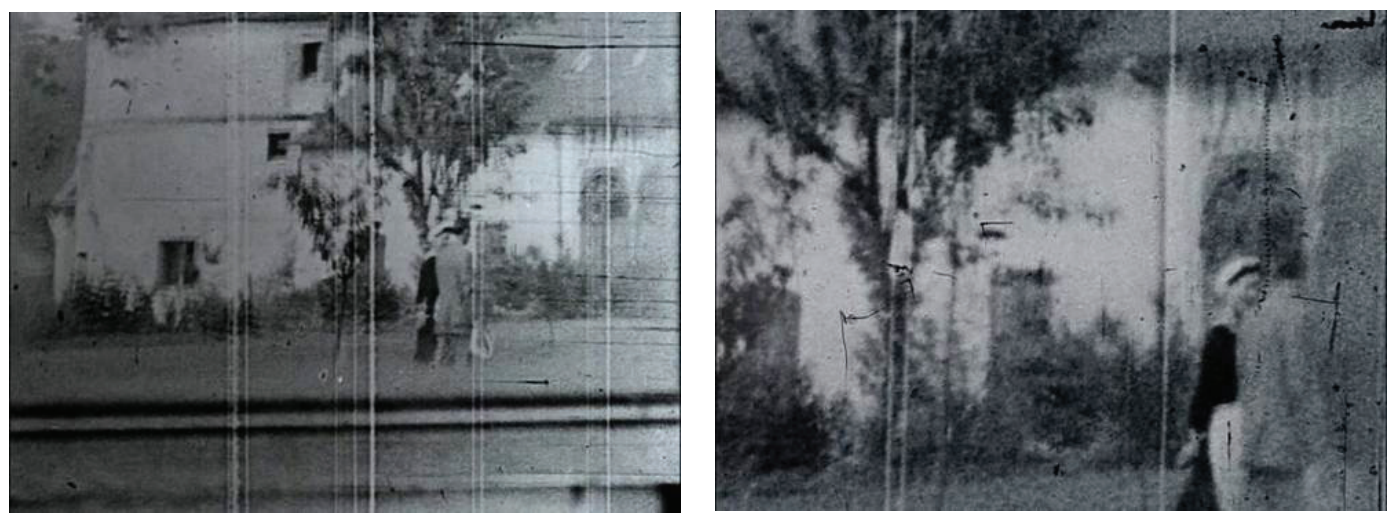

Fonte: Tren de sombras, José Luis Guerin, 1997.

0 espírito inquisidor de Guerin não difere

muito daquele dos historiadores da arte que, por meio de técnicas modernas, como 0 raio $\mathrm{X}$ e câmeras infravermelhas, procuram penetrar nas subcamadas das pinturas e desvendar seus segredos. Uma vez radiografadas, as pinturas podem revelar diferenças significativas entre 0 esboço inicial do pintor, que se faz visível através desses instrumentos tecnológicos, e a versão final do quadro. Assim, desenhos de Rafael e Rembrandt, os quais depois foram descartados e recobertos por camadas de tinta, são trazidos à luz e analisados, como ruínas de cidades submersas encontradas em uma escavação arqueológica. Guerin, ainda que mobilize outro material e outras técnicas, realiza algo parecido, ou seja, sai à procura dos "desenhos" que ficaram mascarados tanto pelas limitações estruturais do cinema ( 0 achatamento do espaço em uma superfície bidimensional; o enquadramento como parcela restrita de uma realidade 
infinitamente maior) quanto pela perda de nitidez da imagem, acarretada por sua deterioração física.

Impossível não pensar no enredo de Blow up, protótipo dessa operação de ampliação fotográfica do detalhe e de dilatação do tempo de observação da imagem. No filme seminal de Antonioni, 0 fotógrafo Thomas (David Hemmings), enquanto analisa as fotografias que fez de um casal em um parque em Londres, percebe um detalhe que destoa do resto da paisagem/imagem. Um pouco antes de revelá-las em seu laboratório, ele descrevera as fotos para seu editor como "apaziguantes" e "estáticas". Mas esses dois adjetivos são contrariados por aquilo que descobre depois de ampliar as fotos: um assassinato se desenrolando sob a aparente tranquilidade do encontro no parque. A emulsão química e a ampliação óptica desvelam um evento que, originalmente, não estava na mira do fotógrafo, mas que sua câmera captou mesmo assim.
0 detalhe anômalo irrompe como um defeito no processo de significação, uma mácula que causa uma ferida hermenêutica na foto, e que só adquire "legitimidade" perceptiva por conta justamente do regime analógico em que está inserida. Esse detalhe que faz ruído é como uma "mancha" que se destaca da paisagem - para tomar emprestado o que Pascal Bonitzer (1982) dizia sobre a fagulha de ativação do suspense em Hitchcock - ou, se quisermos revisitar o conceito barthesiano de punctum, é um pequeno traço que fere o olhar, modifica o regime de atenção do observador e cria uma brecha, uma via de acesso a um extracampo, a alguma coisa que está na imagem sem necessariamente se mostrar (BARTHES, 1984). Há um plano de Blow up em que Thomas dá forma visível a essa experiência do corte perceptivo causado pelo detalhe fulgurante: ele contorna com um lápis o foco de mistério que pescou na imagem, isola da fotografia a mancha, o detalhe que causa um distúrbio visual no quadro (Figura 9).

\section{Figura 9: A mancha na paisagem.}

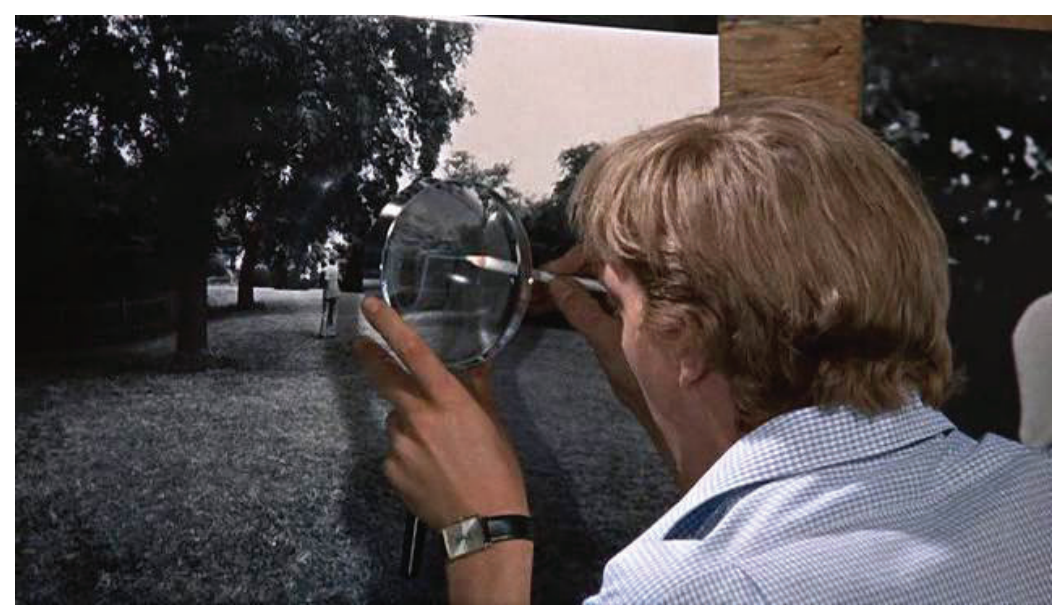

Fonte: Blow up, Michelangelo Antonioni, 1966. 
No começo de Blow up, Thomas encontra um amigo pintor que está trabalhando em uma tela abstrata. 0 pintor explica seu processo: "Não significa nada enquanto estou pintando, apenas uns borrões. Depois, consigo achar alguma coisa que serve de referência, como esta perna. Então tudo começa a se encaixar, a fazer sentido. É como achar uma pista num romance policial". A cena é particularmente elucidativa, pois expõe e esclarece um percurso - da abstração à figuração - que o filme fará, primeiramente em sentido oposto, dinamitando a figura e reencontrando uma espécie de visibilidade anterior, originária, e depois naquele sentido sugerido pelo pintor, redescobrindo a figura a partir de uma "pista" encontrada em meio a uma caótica paisagem de pontos e manchas. Thomas vai selecionando partes das fotografias e ampliando, penetrando cada vez mais fundo tanto no acontecimento registrado pela câmera quanto na matéria constitutiva da imagem. Dos planos abertos, onde 0 que ele tem diante dos olhos nada mais é que um motivo pictórico clássico - paisagem com figuras -, Thomas vai passando aos planos fechados, em que as formas perdem os contornos legíveis e os grãos crescem devorando o conteúdo figurativo da imagem. A sequência demonstra que a própria fotografia comporta, em seu interior, uma tendência de desfiguração da representação, como se estivesse atravessada por forças de "desanalogização" (DUBOIS, 2004, p. 55). As últimas ampliações de Thomas se assemelham ao expressionismo abstrato. É justamente aí, nesse limite, que os detalhes, que antes se dissimulavam no fundo da paisagem, aparecem em primeiro plano e se impõem como a evidência da morte ocorrida no parque. Com a imagem esgarçada ao máximo, surgem a arma do assassino em uma foto (Figura 10) e o corpo da vítima em outra (Figura 11), o grau de nitidez da figura sendo bem maior no primeiro caso que no segundo - o cadáver é menos uma figura do que uma potência de figura, menos uma reprodução mimética do que um traço, um vestígio.

Figuras 10 e 11: A arma do assassino e o corpo da vítima.
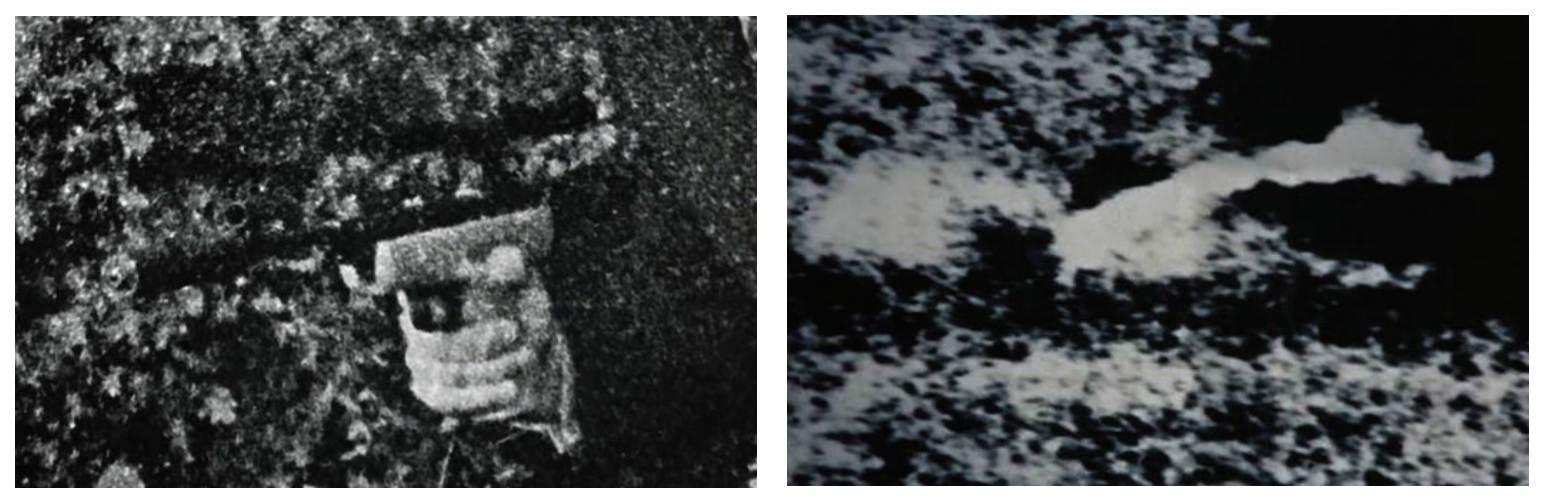

Fonte: Blow up, Michelangelo Antonioni, 1966. 
A fotografia de Thomas, agora, conecta-se com a pintura de seu amigo. Foi preciso mergulhar na matéria, implodir o espaço sistemático desenvolvido desde 0 Renascimento, para só então - estando em fase com um novo tipo de visão plástica - encontrar alguma pista, alguma nesga de sentido. 0s corpos figurados na foto precisaram ser dissolvidos para que, já no limiar da abstração, naquele ponto em que a materialidade própria da imagem - sublinhada e fermentada - havia destruído a legibilidade, outros corpos, antes "invisíveis", pudessem ser encontrados.

0 que aproxima Blow up do expressionismo abstrato é o fato de Antonioni também tematizar o desafio lançado pela interpretação das novas imagens, que, à antiga concepção do quadro como arranjo composicional significante, opõem a técnica do all over, fazendo explodir 0 espaço da representação em uma infinidade de manchas de cor e signos pictóricos reduzidos à sua mais elementar qualidade material. 0 olhar se vê instigado a penetrar por entre as camadas de cor e matéria pictural, a mergulhar nos estratos de pintura em busca de algum elemento revelador. Mas a relação entre 0 olho e 0 quadro se transformou, e a contemplação atenta não tem mais valor de leitura.

No quadro The Deep, de 1953, Jackson Pollock provoca abertamente 0 espectador, convidando-0 a um exercício hermenêutico, mas frustrando-o com a imposição de um muro de pintura impenetrável (Figura 12). 0 título já joga com essa ideia de que a imagem guarda um segredo em suas profundezas, merecendo ser cuidadosamente escrutada (sem falar nas conotações eróticas do quadro). As camadas de cor e de matéria pictórica estariam encobrindo um significado que, para ser desvendado, solicita um trabalho de "hermenêutica arqueológica" (STOICHITA, 2015, p. 201). Entretanto, tudo o que a pintura tem a oferecer, no fim das contas, é sua experiência óptica englobante.

Figura 12: Jackson Pollock, The Deep, 1953, óleo e esmalte sobre tela, 150,7 x 220,4 cm.

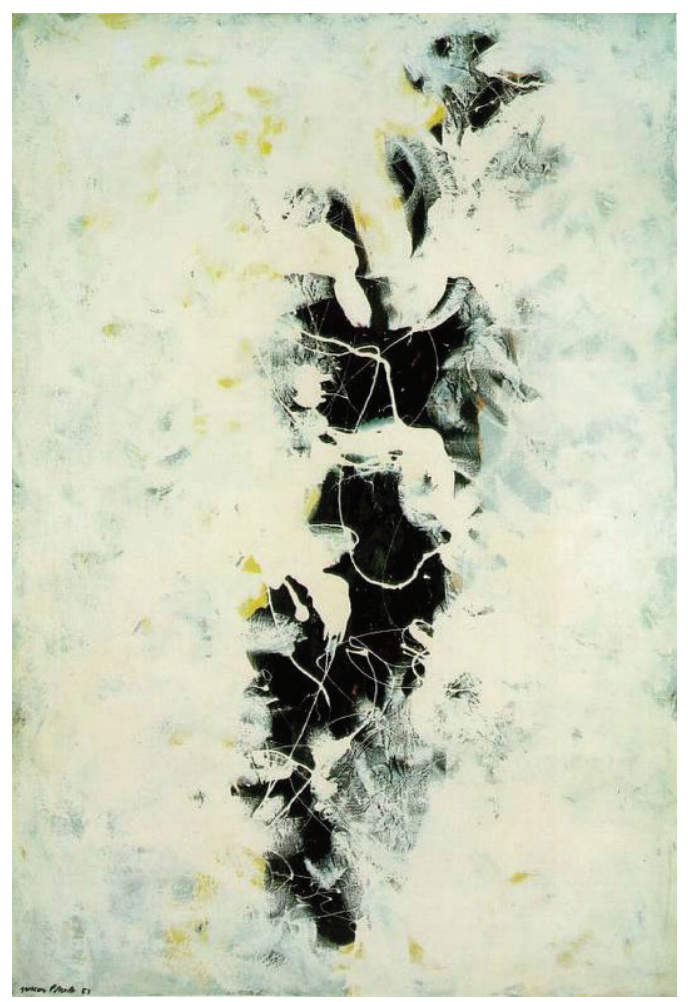

Fonte: Centre Georges Pompidou (Paris).

Em Blow up, uma experiência similar é produzida, só que pelos meios do cinema e da narrativa com imagens em movimento. 0 filme pode ser encarado 
como uma espécie de all over cinematográfico. Quem 0 viu sabe muito bem que a empreitada investigativa do fotógrafo descamba no vazio. Seus negativos e ampliações são roubados, restandolhe apenas uma imagem que não passa de um aglomerado de pontos e manchas. Ele pensava ter descoberto um crime escondido no "fundo" da imagem. Mas o fundo da imagem não é senão uma ilusão óptica produzida em uma superfície bidimensional. Thomas fracassa na tentativa de descortinar o que há por trás da camada mais aparente da realidade; 0 que ele tem à sua disposição é uma fotografia, uma imagem, e uma imagem é uma imagem - nada mais, nada menos.

\section{Entrar na imagem}

Retornando a Tren de sombras: após fermentar os detalhes para vê-los de perto, Guerin buscará outra forma de acessar as cenas da bicicleta e do reflexo no vidro, que consistirá em reconstituílas com atores e reencená-las. Com isso, Guerin se permitirá fazer o que Fleury não fazia: uma decupagem, ou seja, uma fragmentação da cena em planos captados de pontos de vista diferentes. Assim, ele reconstrói, variando o ângulo e a escala das tomadas, o momento em que Hortense passa de bicicleta e acena para Etiénne, com a babá a observá-los dissimulada atrás de uma árvore.

Não satisfeito, Guerin ainda repete a cena paralisando-a, imobilizando os atores no momento crucial em que Fleury (portando a câmera com a qual filmava a cena), Etiénne, Hortense e a babá se alinham em um mesmo eixo visual. Com a cena hieratizada na forma de um tableau vivant, Guerin passeia por dentro dela através de travellings e insere planos nos quais efetua mudanças extremas de ponto de vista, como a buscar o melhor ângulo, o lugar de onde a charada óptica se elucidaria, ou como a explorar, por intermédio de um olhar móvel, uma imagem pausada. 0 conteúdo da cena aparece como um bloco de duração solidificada, um cristal de espaçotempo que pode ser manipulado e avaliado em todas as suas faces. Surpreende, em especial, o plano em que Guerin mostra a cena do ponto de vista da babá escondida na vegetação, um ponto cego do filme de Fleury (Figura 13). É como se Guerin filmasse $o$ dorso da imagem, virasse-a do avesso.

Figura 13: 0 dorso da imagem.

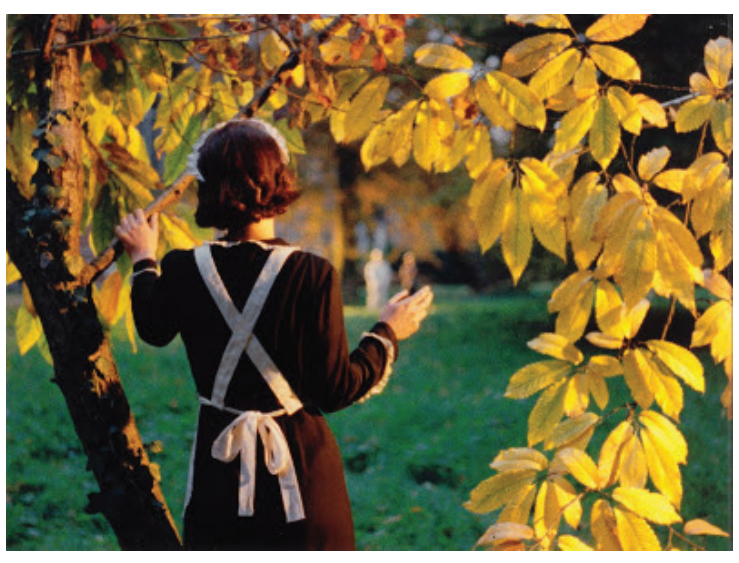

Fonte: Tren de sombras, José Luis Guerin, 1997.

De certa forma, Guerin realiza o sonho de todo investigador de imagens: entrar na imagem, acessá-la como quem visita um espaço e não somente como quem examina visualmente uma 
superfície plana. Se, em um primeiro momento, as estratégias de Guerin se reportavam a Blow $u p$, agora elas parecem remontar a outro filme que apontei como baliza das ficções de análise: $A$ hipótese do quadro roubado.

Inspirado em um ensaio de Pierre Klossowski, $A$ hipótese do quadro roubado se apresenta como uma expedição da câmera de Ruiz por dentro de uma mansão em cujos jardins, cômodos e áreas secretas se acham reconstituídos - através da técnica do tableau vivant (o qual consiste em fazer uma composição pictural ser encarnada por modelos vivos) - os quadros de um pintor, Tonnerre, que foi alvo de escândalo no final do século XIX. A visita é guiada por um erudito colecionador de arte e por uma voz off com a qual ele dialoga. Conforme explica o colecionador, a obra que provocou o escândalo consiste em uma série de sete pinturas conectadas por um fio secreto. Refazendo esse fio, é possível desvendar o motivo obscuro pelo qual os quadros geraram polêmica em sua época.

Porém, um dos quadros está faltando, o "quadro roubado". Logo, a cadeia está interrompida, esburacada, o nexo está quebrado. A montagem, a passagem de uma imagem à outra acusa uma falha, um hiato, um plano de ligação a menos. Assim, o filme coloca em evidência o fato de que "o espaço cinematográfico comporta vazios que são sistematicamente recalcados, 'suturados"” pela montagem, pela organização significante do material filmado (ibid., p. 73). Esse vazio, aqui, fica escancarado, pois efetivamente não pode ser recoberto, uma vez que a cadeia sofre uma interrupção. Se todos os quadros se conectam entre si, a ausência de um deles gera uma situação equiparável a um campo-contracampo em que um dos termos fosse subitamente suprimido, implicando um "campo cego".

0 colecionador não se furta a visitar essa cena ausente e a estabelecer seu lugar na série (ela é a quarta pintura das sete, ou seja, está exatamente no meio da narrativa). 0 quadro roubado é representado por um cômodo vazio, desertado pelas figuras humanas. Uma vez que o colecionador nunca viu a pintura original, ele só pode imaginá-la. 0 espaço vazio que substitui o quadro roubado é um desafio lançado à imaginação e à especulação.

Ao mostrar o tableau vivant seguinte, que representa o quadro recusado pelo Salão de 1887 e desencadeador do escândalo, o colecionador afirma que há algo de inquietante na cena cotidiana ali representada, como se alguma das personagens do quadro tivesse acabado de cometer um "ato repreensível" (Figura 14). A partir daí, tudo parece corrompido (afinal de contas, uma imagem só é inocente até que se comece a interpretá-la). 0 colecionador se interroga: "Será que essa cena familiar aparentemente banal é realmente inocente? Podemos assegurar que ela está totalmente isenta de certos aspectos obscuros?". Ora, sem precisar enunciá-la verbalmente, apenas trabalhando com 
as ferramentas visuais que já comentamos, Guerin dirige a mesmíssima indagação ao filme de família que analisa em Tren de sombras. Ele também coloca sob suspeita a inocência da cena familiar contida nas imagens que investiga.

Figura 14: A cena familiar "inocente".

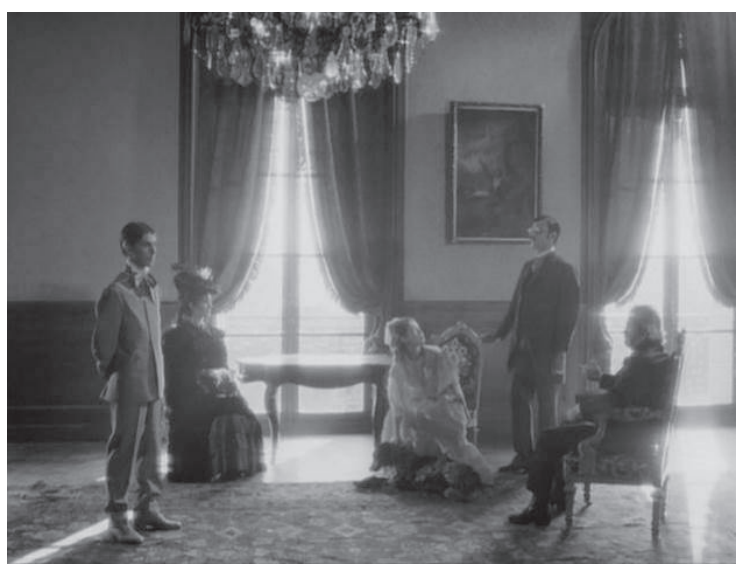

Fonte: A hipótese do quadro roubado, Raúl Ruiz, 1978.

A ideia de Guerin de utilizar o tableau vivant como um dispositivo de mise en scène que permite uma decomposição do ponto de vista já existia, portanto, em A hipótese do quadro roubado: recriando as pinturas com os recursos da mise en scène cinematográfica, Ruiz "decupa" os tableaux vivants; sua câmera invade as pinturas, aproxima-se das personagens, filma-as por novos ângulos e pontos de vista, ou seja, mostra-as de uma forma que difere daquela que consta no quadro original. Trocando a platitude da imagem pintada por uma cenografia tridimensional, e libertando 0 observador da unidade imutável do ponto de vista pictórico, o tableau vivant traz a possibilidade de se percorrer a cena, de se descobrirem os ângulos mortos. 0 estatismo das poses é compensado pela mobilidade e multiplicidade dos pontos de vista. 0 próprio colecionador entra nas pinturas e deambula entre os modelos. Ele chega a acender a luz para desfazer o claro-escuro de um dos quadros, tornando a iluminação homogênea e permitindo que se enxerguem melhor os detalhes e gestos (figuras 15 e 16).

\section{Figuras 15 e 16: 0 colecionador acende a luz de um tableau vivant.}
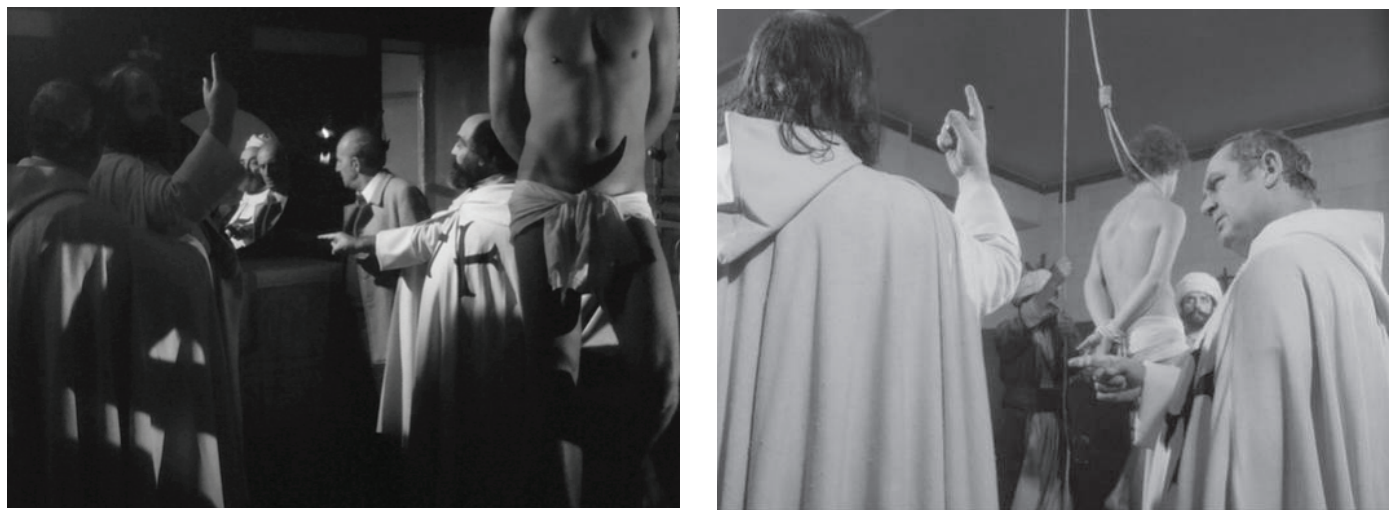

Fonte: A hipótese do quadro roubado, Raúl Ruiz, 1978. 
Em Blow up , o fotógrafo bem que gostaria de poder dar a volta nos "modelos" e ver a cena por outro ângulo, para tentar entendê-la melhor. Porém, ele esbarrava na platitude da fotografia, no seu espaço achatado em duas dimensões. Em A hipótese do quadro roubado e Tren de sombras, as imagens são transpostas para 0 espaço tridimensional, 0 que permite à câmera entrar nelas e variar o ponto de vista. Contudo, tanto a série de quadros interrompida no filme de Ruiz, esburacada em seu centro pela falta de uma das pinturas, quanto o filme familiar usado por Guerin, com suas elipses, "desmontagens", suas partes que faltam devido à degradação do material, enfim, tanto um conjunto de imagens quanto o outro remetem ao mural de fotografias de Thomas em Blow up, também ele assombrado por imagens ausentes, hiatos. Todos os três, o fotógrafo do filme de Antonioni, o colecionador de arte do filme de Ruiz e 0 detetive de imagens personificado por Guerin, estão condenados, em última instância, à eterna suposição e à dúvida.

\section{Adeus à película e ao século XX}

Tren de sombras, como já dissemos, investe nas propriedades intrínsecas do suporte fílmico, cuja existência precária mas duradoura (haja vista a sobrevivência das imagens de Fleury, mesmo que em condições limítrofes) constitui o seu assunto um filme sobre a película, se um único tema tiver de ser-lhe atribuído. Guerin dialoga aí com certa tradição do cinema estrutural:

Uma série de filmes de found footage visa precisamente essa dimensão melancólica da imagem fílmica, duplamente exposta à sua desaparição: materialmente, como "última" cópia relegada ao esquecimento e ao abandono no fundo de arquivo; imaterialmente, na projeção de sua permanente inapreensibilidade. Hoje, 0 suporte de nitrocelulose facilmente inflamável que se utilizava até os anos 1950 está em vias de murchar, coagular, colar, e esse processo em si mesmo se tornou objeto de tratamento artístico [...]. (BLÜMLINGER, 2013, p. 50-51)

0 momento em que Guerin atinge 0 ápice de sua motivação estética é aquele em que fixa 0 rosto de Hortense, retém seu semblante em vias de desaparecer por conta da continuidade irrefreável do filme ou da "degradação biológica" da película, que ameaça apagar o rosto da jovem no processo geral de perda e estrago do suporte material em que sua imagem ficara gravada (figuras 17 e 18). 0 estado precário da película, antes de atrapalhar ou prejudicar o filme, potencializa a beleza dos primeiros planos do rosto de Hortense, essa beleza, como diria Jean Epstein (1974, p. 91), "polarizada como uma luz" pelo cinema. 


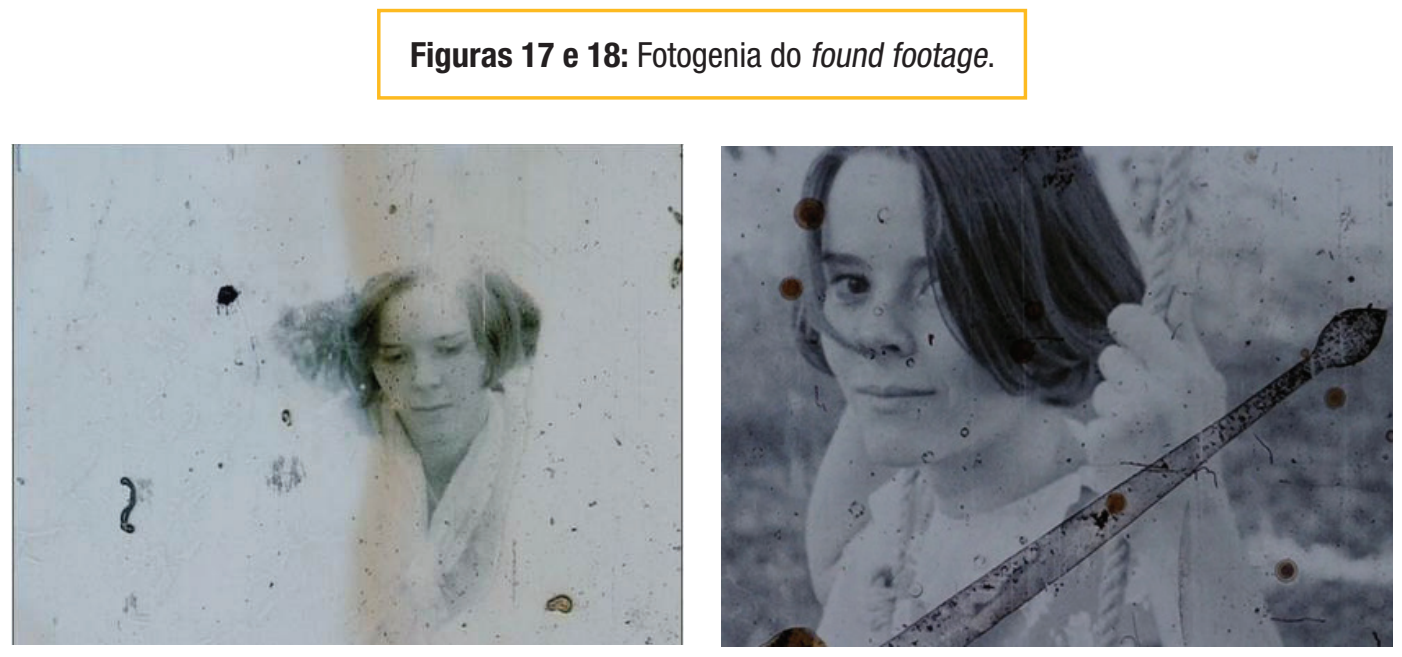

Fonte: Tren de sombras, José Luis Guerin, 1997.

Nessas imagens, 0 cineasta catalão antecipa

o projeto que desenvolveria sistemática e obsessivamente no "díptico de Sylvia" (Unas fotos en la ciudad de Sylvia e En la ciudad de Sylvia, ambos de 2007): a arte de gravar um rosto, de salvá-lo da desaparição inexorável, como fica claro nos momentos em que ele mostra o rosto de uma mulher por trás de um trem que está

Figuras 19: Síntese de movimento e fixidez.

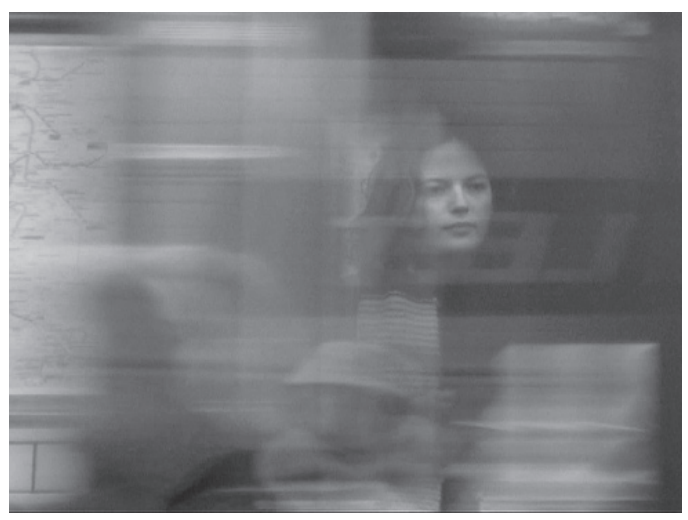

Fonte: Unas fotos en la ciudad de Sylvia, José Luis Guerin, 2007. passando à sua frente (figuras 19 e 20). A moça se acha parada na plataforma, mas o trem está em movimento, criando um efeito interessante pelo contraste entre o corpo estático e os corpos e objetos que passam em alta velocidade sem dar tempo suficiente para que a câmera apreenda sua imagem de forma legível - eles deixam para trás apenas um traço, um rastro.

Figura 20: Uma metáfora do cinema.

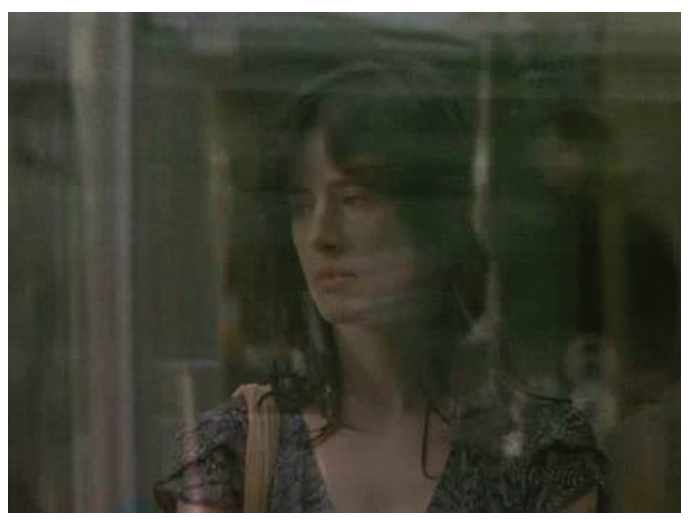

Fonte: Jose Luis Guerin, En la ciudad de Sylvia, 2007. 
Esses planos, à semelhança daqueles de Tren de sombras, evocam o próprio trabalho da imagem cinematográfica e dos efeitos do tempo sobre ela. No entanto, aqui a película não está em processo de deterioração: oflou na imagem é produzido pela passagem do trem, meio de transporte que emblematiza a era industrial-mecânica e está irrecusavelmente ligado ao mesmo contexto tecnológico e perceptivo em que se deu a invenção do cinema. 0 trem aparece com frequência, nos primeiros filmes, como signo da modernização dos sentidos e da alteração da percepção subjetiva no final do século XIX, assim como das profundas transformações sociais, econômicas e culturais então em curso. A afinidade entre 0 cinema e o trem se dá não só de um ponto de vista iconográfico, mas, sobretudo, funcional:

Viajante imóvel que assiste ao espetáculo enquadrado da paisagem que ele atravessa, 0 usuário da estrada de ferro do século XIX anuncia o espectador [do cinema]. Esse viajante confrontado a vistas panorâmicas e dinâmicas deve aceitar perder o primeiro plano, borrado pela velocidade: 0 trem the aparece como uma força que destrói o espaço e o tempo. (BLÜMLINGER, 2013, p. 88)

As imagens de Guerin no "díptico de Sylvia", com o primeiro plano borrado à frente dos rostos femininos, são então um comentário estrutural sobre a analogia do cinema, "uma máquina que ordena 0 olhar, que produz linearidade e movimento" (ibid.), com o trem.

Em Tren de sombras, há apenas uma cena em que aparece 0 trem, e que consiste em uma série de planos em que Fleury ensaia uma gag tendo Etiénne como ator: um homem, aparentemente atrasado para sua viagem, sai correndo atrás do trem, que corta a paisagem e cruza o campo visual deixando para trás não mais que um rastro de fumaça. Guerin reconhece aí uma metáfora do cinema, e não se furta a colocar o trem no título do filme. 0 que ele elabora em Tren de sombras é não apenas um modelo experimental de reflexão metafillmica, mas também uma forma renovada de estudo visual e investigação de imagens: uma máquina hermenêutica baseada tanto nas capacidades do cinema como meio de intensificação perceptiva quanto nas vertigens interpretativas potencialmente contidas na imagem filmica.

\section{Referências}

AIDELMAN, Núria. En quête d'un visage. Images de ce qui fuit: A propos de Tren de sombras. Images documentaires, n. 73-74, Paris, 2012, pp. 45-50.

ARASSE, Daniel. Le Détail. Pour une histoire rapprochée de la peinture. Paris: Flammarion, 1996.

BARTHES, Roland. A câmara clara. Rio de Janeiro: Nova Fronteira, 1984.

BLÜMLINGER, Christa. Cinéma de seconde main. Esthétique du remploi dans l'art du film et des nouveaux médias. Paris : Klincksieck, 2013.

BONITZER, Pascal. Le champ aveugle. Paris:

Gallimard; Cahiers du Cinéma, 1982.

BRENEZ, Nicole. Puissance d'une forme cinématographique: l'étude visuelle [d'Al Razutis à Brian De Palma]. In: AUMONT, Jacques (org.). Pour un cinéma comparé. Influences et répétitions. Paris: Cinémathèque Française, 1996. 
DUBOIS, Philippe. Cinema, vídeo, Godard. São Paulo: Cosac Naify, 2004.

0 ato fotográfico e outros ensaios. $14^{\mathrm{a}} \mathrm{ed}$. Campinas, SP: Papirus, 2012.

EPSTEIN, Jean. Écrits sur le cinéma. Tome 1: 1921-

1947. Paris: Seghers, 1974.

JOURNOT, Marie-Thérèse. Tren de sombras. El espectro de Le Thuit. Re-monter le temps aux origines du cinéma. CinémAction, n. 122, 2007, pp. 269-274.

ROBERT, Valentine. Le tableau vivant chez Raoul Ruiz: l'extension de la perception. Décadrages, n. 15, 2009, pp. 38-40.

RUIZ, Raúl. Poetics of cinema. Paris: Éditions Dis Voir, 2005.

STOICHITA, Victor I. L'Effet Sherlock Holmes.

Variations du regard de Manet à Hitchcock. Paris:

Hazan, 2015.

WILSON, Michael. If the paintings could talk...

Londres: The National Gallery, 2008. 


\section{Fictions of analysis: detail, visual intrigue, and "hermeneutic archeology" in Tren de sombras (1997)}

\section{Abstract}

The article focuses on what one might call a "fiction of analysis": a narrative that concentrates on the investigation of an image or a set of images, which are examined through a curious, hyperbolic gaze, willing for optical intrigue and surprising discoveries. We will see how this form of gaze, typical of Western visual modernity, manifests itself in Tren de Sombras (Jose Luis Guerin, 2007), whose cinematographic precursors can be traced back to Blow Up

(Michelangelo Antonioni, 1966) and The Hypothesis of the Stolen Painting (Raul Ruiz, 1978). The aim is to show how these films elaborate an experimental model for visual investigation and meta-filmic analysis.

\section{Keywords}

Filmic support. Optical investigation.

Aesthetic Hermeneutics.

\section{Ficciones de análisis:} detalle, intriga visual y "arqueología hermenéutica" en Tren de sombras (1997)

\section{Resumen}

El artículo trata de lo que podemos llamar de una "ficción de análisis": una narrativa concentrada en la investigación de una imagen o de un conjunto de imágenes, las cuales son examinadas por una mirada exacerbada y curiosa, hambrienta por intrigas ópticas y descubrimientos sorprendentes. Veremos como tal mirada, típica de la modernidad visual en el Occidente, se manifiesta en Tren de sombras (Jose Luis Guerin, 2007), cuyos principales precursores cinematográficos son Blow up (Michelangelo Antonioni, 1966) y Hipótesis del cuadro robado (Raul Ruiz, 1978). El objetivo es demostrar cómo esas películas proveen un modelo experimental de investigación visual y análisis metafílmica.

\section{Palabras clave}

Soporte fílmico. Investigación óptica.

Hermenéutica estética. 


\section{Expediente}

A revista E-Compós é a publicação científica em formato eletrônico da Associação Nacional dos Programas de Pós-Graduação em Comunicação (Compós). Lançada em 2004, tem como principal finalidade difundir a produção acadêmica de pesquisadores da área de Comunicação, inseridos em instituições do Brasil e do exterior.

\section{E-COMPÓS I www.e-compos.org.br I E-ISSN 1808-2599}

Revista da Associação Nacional dos Programas de Pós-Graduação em Comunicação.

Brasília, v.20, n.1, jan./abr. 2017.

A identificação das edições, a partir de 2008, passa a ser volume anual com três números.

Indexada por Latindex I www.latindex.unam.mx

\section{CONSELHO EDITORIAL}

Alda Cristina Silva da Costa, Universidade Federal do Pará, Brasil Alfredo Luiz Paes de Oliveira Suppia, Universidade Estadual de Campinas, Brasil Álvaro Larangeira, Universidade Tuiuti do Paraná, Brasil Ana Carolina D. Escosteguy, Pontifícia Universidade Católica do Rio Grande do Sul, Brasil Ana Regina Barros Rego Leal, Universidade Federal do Piauí, Brasil Ana Carolina Rocha Pessôa Temer, Universidade Federal de Goiás, Brasil Andrea França, Pontifícia Universidade Católica do Rio de Janeiro, Brasil André Luiz Martins Lemos, Universidade Federal da Bahia, Brasil Angela Cristina Salgueiro Marques, Faculdade Cásper Libero, Brasil Ângela Freire Prysthon, Universidade Federal de Pernambuco, Brasil Antonio Carlos Hohlfeldt, Pontifícia Universidade Católica do Rio Grande do Sul, Brasil Arthur Ituassu, Pontifícia Universidade Católica do Rio de Janeiro, Brasil Bruno Campanella, Universidade Federal Fluminense, Brasil Cláudio Novaes Pinto Coelho, Faculdade Cásper Líbero, Brasil Carlos Eduardo Franciscato, Universidade Federal de Sergipe, Brasil Denise Tavares da Silva, Universidade Federal Fluminense, Brasil Eduardo Vicente, Universidade de São Paulo, Brasil Eliza Bachega Casadei, Escola Superior de Propaganda e Marketing - SP, Brasil Elizabeth Nicolau Saad Corrêa, Universidade de São Paulo, Brasil Erick Felinto de Oliveira, Universidade do Estado do Rio de Janeiro, Brasil Erly Vieira Júnior, Universidade Federal do Espirito Santo, Brasil Francisco de Assis, FIAM-FAAM Centro Universitário, Brasil Francisco Elinaldo Teixeira, Universidade Estadual de Campinas, Brasil Frederico de Mello Brandão Tavares, Universidade Federal de Ouro Preto, Brasil Gabriela Reinaldo, Universidade Federal do Ceará, Brasil Gilson Vieira Monteiro, Universidade Federal do Amazonas, Brasil Gustavo Daudt Fischer, Universidade do Vale do Rio dos Sinos, Brasil Igor Sacramento, Fundação Oswaldo Cruz, Brasil Itania Maria Mota Gomes, Universidade Federal da Bahia, Brasil Jiani Adriana Bonin, Universidade do Vale do Rio dos Sinos, Brasil José Afonso da Silva Junior, Universidade Federal de Pernambuco, Brasil
José Luiz Aidar Prado, Pontifícia Universidade Católica de São Paulo, Brasil Juçara Gorski Brittes, Universidade Federal de Ouro Preto, Brasil Laura Loguercio Cánepa, Universidade Anhembi Morumbi, Brasil Liziane Soares Guazina, Universidade de Brasilia, Brasil Luíza Mônica Assis da Silva, Universidade Católica de Brasília, Brasil Maria Ataide Malcher, Universidade Federal do Pará, Brasil Maria Elisabete Antonioli, Escola Superior de Propaganda e Marketing - SP, Brasil Maria das Graças Pinto Coelho, Universidade Federal do Rio Grande do Norte, Brasil Marcel Vieira Barreto Silva, Universidade Federal da Paraíba, Brasil Marcia Tondato, Escola Superior de Propaganda e Marketing, Brasil Marli Santos, Universidade Metodista de São Paulo, Brasil Márcio Souza Gonçalves, Universidade do Estado do Rio de Janeiro, Brasil Mauricio Mario Monteiro, Universidade Anhembi Morumbi, Brasil Mauricio Ribeiro da Silva, Universidade Paulista, Brasil Mauro de Souza Ventura, Universidade Estadual Paulista, Brasil Mayka Castellano, Universidade Federal Fluminense, Brasil Micael Maiolino Herschmann, Universidade Federal do Rio de Janeiro, Brasil Mozahir Salomão Bruck, Pontifícia Universidade Católica de Minas Gerais, Brasil Nísia Martins Rosario, Universidade Federal do Rio Grande do Sul, Brasil Potiguara Mendes Silveira Jr, Universidade Federal de Juiz de Fora, Brasil Raquel Ritter Longhi, Universidade Federal de Santa Catarina, Brasil Regiane Regina Ribeiro, Universidade Federal do Paraná, Brasil Roberto Elísio dos Santos, Universidade Municipal de São Caetano do Sul, Brasil Rodolfo Rorato Londero, Universidade Estadual de Londrina, Brasil Sérgio Luiz Gadini, Universidade Estadual de Ponta Grossa, Brasil Simone Maria Andrade Pereira de Sá, Universidade Federal Fluminense, Brasil Simone Maria Rocha, Universidade Federal de Minas Gerais, Brasil Suzana Reck Miranda, Universidade Federal de São Carlos, Brasil Tarcyanie Cajueiro Santos, Universidade de Sorocaba, Brasil Tatiana Oliveira Siciliano, Pontifícia Universidade Católica do Rio de Janeiro, Brasil Veneza Mayora Ronsini, Universidade Federal de Santa Maria, Brasil

\section{CONSELHO CIENTÍFICO}

Cristiane Freitas Gutfreind, Pontifícia Universidade Católica do Rio Grande do Sul, Brasil Eduardo Morettin, Universidade de São Paulo, Brasil

Felipe Costa Trotta, Universidade Federal Fluminense, Brasil Irene de Araújo Machado, Universidade de São Paulo, Brasil

\section{COMISSÃO EDITORIAL}

Eduardo Antonio de Jesus, Universidade Federal de Minas Gerais, Brasil Marco Antonio Roxo da Silva, Universidade Federal Fluminense, Brasil Osmar Gonçalves dos Reis Filho, Universidade Federal do Ceará, Brasil

\section{CONSULTORES AD HOC}

Kelly C. de Souza Prudencio, Universidade Federal do Paraná, Brasil Francisco P. Jamil A. Marques, Universidade Federal do Paraná, Brasil Tiago Quiroga F. Neto, Universidade de Brasília, Brasil

\section{EQUIPE TÉCNICA}

ASSISTENTE EDITORIAL Márcio Zanetti Negrini REVISÃO DE TEXTOS Press Revisão EDITORAÇÃO ELETRÔNICA Roka Estúdio IMAGEM DE CAPA Silas de Paula

\section{COMPÓS I www.compos.org.br}

Associação Nacional dos Programas de Pós-Graduação em Comunicação

Presidente

Edson Fernando Dalmonte

Programa de Pós-Graduação em Comunicação

e Cultura Contemporânea - UFBA

edsondalmonte@uol.com.br

Vice-presidente

Cristiane Freitas Gutfreind

Programa de Pós-Graduação em Comunicação Social - PUC-RS cristianefreitas@pucrs.br

Secretário-Geral

Rogério Ferraraz

Programa de Pós-Graduação em Comunicação

Universidade Anhembi Morumbi

rogerioferraraz@anhembimorumbi.edu.br

CONTATO I revistaecompos@gmail.com 